\title{
Penataan jalur pejalan kaki untuk mendukung Green Campus di kampus Universitas Diponegoro Tembalang
}

\author{
Nararya Adi Prasetya ${ }^{1}$, P. Purwanto ${ }^{2}$, Maryono Maryono ${ }^{3}$ \\ ${ }^{1}$ Magister Ilmu Lingkungan, Sekolah Pascasarjana, Universitas Diponegoro, Semarang-Indonesia \\ ${ }^{2}$ Departemen Teknik Kimia, Fakultas Teknik, Universitas Diponegoro, Semarang-Indonesia \\ ${ }^{3}$ Departemen Teknik Perencanaan Wilayah dan Kota, Fakultas Teknik, Universitas Diponegoro, \\ Semarang-Indonesia \\ *Correspondent email : nararyaadi@students.undip.ac.id
}

Diterima: 26 Januari 2021| Disetujui: 28 April 2021 | Diterbitkan: 30 April 2021

\begin{abstract}
One approach to realizing a green campus is by providing a comfortable space for nonmotorized transportation. Walking is the cheapest, low-emission non-motorized transportation, so accessibility to pedestrians should be prioritized. Providing more space for pedestrians which will change the orientation of road infrastructure that has been more pro-motorized. Diponegoro University, which is the green campus pilot project of the Ministry of Research, Technology and Higher Education, has complete pedestrian paths. However, the current condition is still not appropriately utilised because the movement of academicians is still using motorized vehicles. To preserving the orientation of the existing green campus, it is necessary to evaluate the pedestrian path that is suitable by regulation physically. The results of research on pedestrian paths at the Undip Tembalang Campus indicate that it is required to repair and change the road design that is related to the comfort of people walking, and affects how pedestrian paths are used. Official regulations and policies from the campus will also have an impact on motorized vehicle use. Changes to empower those in the campus environment and energy-efficient actions are carried out by improving the accessibility of campus residents to use public transportation and nonmotorized transportation to campus.
\end{abstract}

Keywords: green campus; pedestrian ways; Diponegoro University

Ruang publik yang dapat menjadi penghubung antarruang dalam suatu kawasan dan merupakan akses antarmoda transportasi adalah jalur pejalan kaki. Kota-kota besar di dunia seperti Singapura, Barcelona, Tokyo, Seoul, memprioritaskan para pejalan kaki, agar nyaman untuk berjalan pada koridorkoridor kota tanpa perlu merasakan kecemasan. Disamping itu berjalan kaki adalah tipe transportasi yang paling hijau dan berkelanjutan (Rafiemanzelat et al., 2017) secara tidak langsung mampu mengurangi polusi karena berkurangnya penggunaan kendaraan bermotor yang menimbulkan emisi gas buang. Pada keseharian manusia yang melakukan perjalanan memiliki titik awal hingga tempat tujuan yang pasti membutuhkan satu bagian untuk berjalan.

Pengertian secara umum dari green campus adalah kampus yang memiliki konsep wawasan lingkungan guna mengurangi dampak dari pemanasan global dengan melakukan praktik pengelolaan dan pelestarian lingkungan yang mendukung keberlanjutan dalam institusi pendidikan (Wimala et al., 2016). Green campus tidak terlepas dari pembahasan topik sustainable berkembang luas dan menjadi topik yang menarik di seluruh dunia, termasuk pada era pertengahan tahun '90an, kampus-kampus mulai memasukkan unsur 'sustainable' dalam program dan perencanaan kebijakan strategi, hingga menyediakan bermacam-macam fasilitas yang memiliki tema berkelanjutan untuk sivitas akademika-nya (Marrone et al., 2018) (Leal Filho et al., 2015).

Tidak hanya mendesain kampus yang baik, kebijakan 'sustainable' tidak lepas dari membuat lingkungan yang nyaman (Göçer et al., 2019). Kenyamanan adalah hal penting (Corazza et al., 2016), mengingat mayoritas mahasiswa maupun dosen/staf pengajar meluangkan sebagian besar waktunya berada di kampus (Shamsuddin et al., 2012)(Murwadi \& Dewancker, 2017). Jalur pejalan kaki memiliki manfaat dari segi ruang publik untuk berinteraksi antarsivitas, jaringan akses dalam internal kawasan kampus dan manfaat dari segi lingkungan karena memberikan alternatif moda transportasi tanpa emisi(Soni \& Soni, 2016)(Ridhosari \& Rahman, 2020). 
Universitas Diponegoro (Undip) memiliki perencanaan jangka panjang untuk mengaplikasikan pengendalian lingkungan menuju green and sustainable campus. Tahap awal, Undip dirasa perlu menata kembali akses yang baik bagi pejalan kaki karena 1) memudahkan sivitas akademika untuk menjangkau fasilitas kampus tanpa kendaraan bermotor, 2) Kampus Undip Tembalang sudah memiliki 4 (empat) kelas jalur yang menghubungkan keseluruhan bangunan, tetapi kondisinya masih perlu ditingkatkan, dan 3) sebagai salah satu bagian dari ruang terbuka yang menintegrasikan antarmoda transportasi serta mobilitas bagi pengguna jalan tidak menggunakan kendaraan bermotor.

\section{METODE PENELITIAN}

\section{Area Studi}

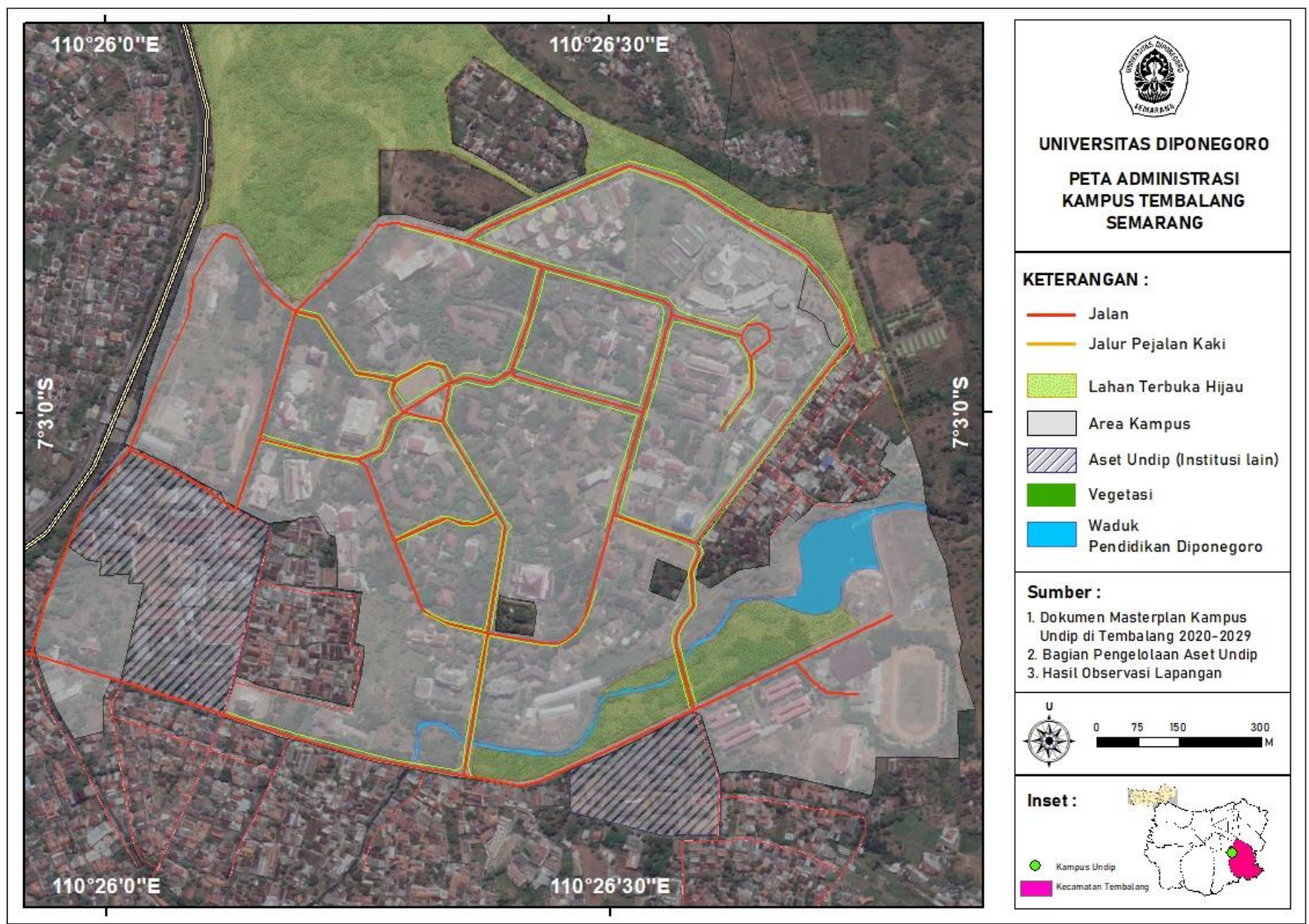

Gambar 1. Peta administrasi kampus Undip di Tembalang

Wilayah studi penelitian ini berada di lingkungan Universitas Diponegoro (UNDIP) Kampus Tembalang. Kampus UNDIP Tembalang terletak di bagian selatan wilayah Kota Semarang (BWK VI) yang terletak kurang lebih $11 \mathrm{~km}$ dari Simpang Lima Semarang (pusat kota). Sebagaimana kita ketahui, Semarang memiliki dua ciri geografis yaitu dataran rendah (pesisir) di bagian utara dan perbukitan di bagian selatan. Kawasan Kampus Undip Tembalang ini termasuk dalam kawasan yang mempunyai kontur bervariasi. Sebagai kawasan pendidikan, area Tembalang yang menjadi lokasi Kampus Undip telah menjadi pusat pertumbuhan kota baru di wilayah Semarang bagian selatan.

\section{Pengumpulan Data}

Data penelitian ini diperoleh dari observasi langsung yang dilakukan selama bulan Februari-Maret 2020 di wilayah Kampus Undip Tembalang. Data spasial juga digunakan untuk memetakan jalur pejalan kaki dan analisis deskriptif digunakan untuk menggambarkan kondisi jalur pejalan kaki di sekitar Kampus Undip Tembalang.

\section{HASIL DAN PEMBAHASAN}

Awal pembangunan Kampus Undip Tembalang sudah merencanakan strategi menuju kampus yang berkelanjutan dengan menyediakan jalur pejalan kaki yang menghubungkan seluruh kawasan kampus. 
Jalur pejalan kaki menjadi aspek penting dalam pengendalian lingkungan dan transportasi internal kampus, mengingat ada 13 Fakultas dan 165 Program studi, sehingga Kampus Tembalang memiliki kepadatan tinggi. Setidaknya terdapat 4 (empat) koridor jalan di Kampus Tembalang yang dilengkapi jalur pejalan kaki untuk memfasilitasi sivitas akademika, yaitu Koridor Jalan Utama, Koridor Penghubung Antarfakultas, Koridor Jalan Lingkar, dan Koridor Penghubung Antargedung. Namun dalam pembahasan penelitian ini lebih difokuskan untuk 2 (dua) koridor utama, yaitu Jalan Utama dan Penghubung Antarfakultas karena pada 2 koridor tersebut memiliki potensi untuk dilalui seluruh sivitas akademika Kampus Tembalang. Koridor Jalan Utama memiliki 2 (dua) tipe ruas jalan yang berbeda, yaitu ruas utara dan selatan. Koridor Penghubung Antarfakultas juga dibedakan menjadi 2 (dua) ruas jalan barat dan timur.

Penilaiannya berdasarkan 5 (lima) variabel yang terdiri dari :

Tabel 1. Variabel Penelitian

\begin{tabular}{|c|c|c|c|}
\hline No & Variabel & Indikator Penilaian & Sumber \\
\hline 1 & $\begin{array}{l}\text { Peletakan jalur pejalan } \\
\text { kaki }\end{array}$ & $\begin{array}{l}1 \text { sisi } \\
2 \text { sisi }\end{array}$ & (Setyowati et al., 2013) \\
\hline 2 & Pengaman pejalan kaki & $\begin{array}{l}\text { Area vegetasi } \\
\text { Pagar } \\
\text { Atap }\end{array}$ & $\begin{array}{l}\text { (Setyowati et al., 2013; Yilmaz et } \\
\text { al., 2016) }\end{array}$ \\
\hline 3 & $\begin{array}{l}\text { Konektivitas jalur pejalan } \\
\text { kaki }\end{array}$ & $\begin{array}{l}\text { Penyeberangan } \\
\text { Persimpangan } \\
\text { Ketersediaan moda transportasi } \\
\text { umum }\end{array}$ & (Cambra \& Moura, 2020) \\
\hline 4 & Atribut jalur pejalan kaki & $\begin{array}{l}\text { Fasilitas difabel } \\
\text { Penerangan } \\
\text { Bangku } \\
\text { Tempat berteduh }\end{array}$ & (D’Orso \& Migliore, 2020) \\
\hline 5 & $\begin{array}{l}\text { Kondisi fisik jalur pejalan } \\
\text { kaki }\end{array}$ & $\begin{array}{l}\text { Desain } \\
\text { Lebar } \\
\text { Kebersihan } \\
\text { Permukaan }\end{array}$ & \begin{tabular}{lccc} 
(Pedoman & \multicolumn{2}{r}{ Perencanaan, } \\
Penyediaan, dan & \multicolumn{2}{r}{ Pemanfaatan } \\
Prasarana dan & Sarana & Jaringan \\
Pejalan Kaki & di & Kawasan \\
Perkotaan, 2014) & &
\end{tabular} \\
\hline
\end{tabular}

Sumber: Hasil Analisis Penyusun, 2020

\section{Koridor Jalan Utama}

Koridor Jalan Utama Undip berbentuk boulevard dengan panjang 1.169,09 meter yang terbagi menjadi 2 (dua) ruas, utara dan selatan. Jalur pejalan kaki pada koridor jalan utama berada dikedua sisi jalan. Jalan utama membelah Kampus Tembalang menjadi 2 bagian yaitu barat dan timur, dengan pusatnya terletak di Widya Puraya (Rektorat) sebagai landmark Kampus Tembalang. Vegetasi sepanjang koridor mengarahkan pada landmark tersebut dan menghubungkan gedung-gedung perkantoran pusat dan Fakultas Teknik. Jalur pejalan kaki yang ada dalam koridor utama menghubungkan jalur pejalan kaki pada koridor jalur lingkar luar yang ada di sisi selatan, termasuk fasilitas Masjid Kampus. Jalur pejalan kaki di koridor utama juga terhubung dengan koridor jalur pejalan kaki penghubung antarfakultas dan penghubung antargedung 
ZONA

Jurnal Lingkungan

ISSN : 2502-6496 (Print) | 2502-6496 (Online)

Volume 5, No 1, April 2021, p. 12-20

http://zona.pelantarpress.co.id

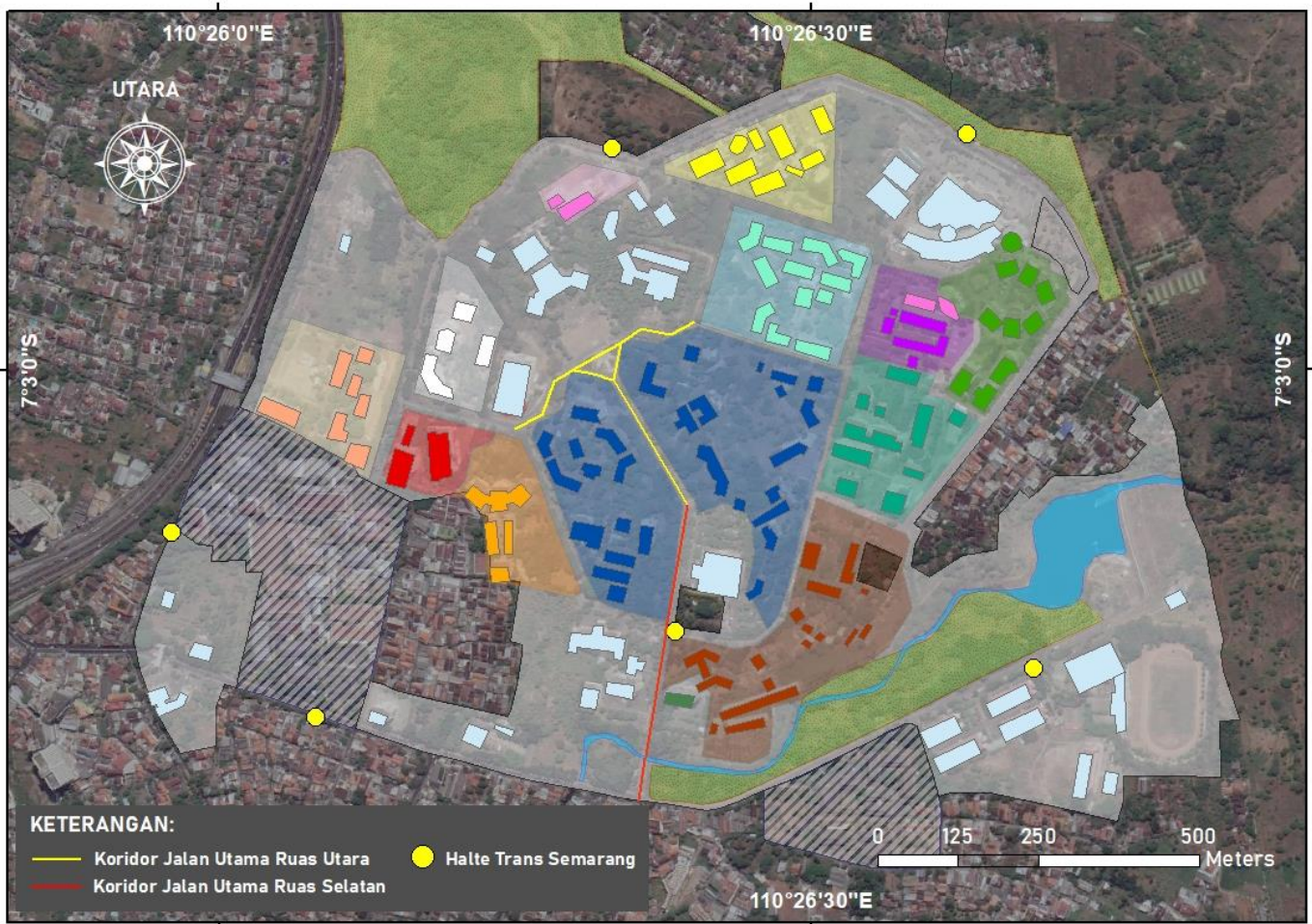

Gambar 2. Peta jalan utama kampus Undip

\section{Ruas Utara}

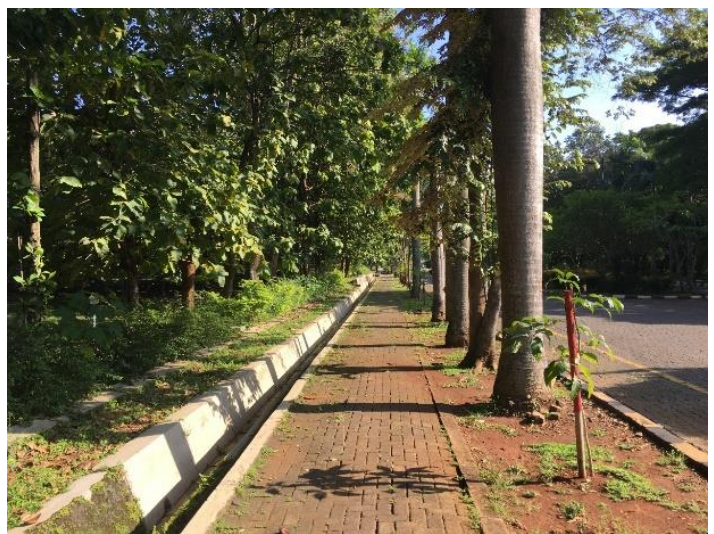

Gambar 3. Jalur pejalan kaki pada koridor jalan utama kampus ruas utara

Jalur pejalan kaki di ruas utara dengan tipe sidewalk terdapat pada kedua sisi jalan, dengan lebar masing-masing 2 meter dan konstruksinya menggunakan paving blok dengan beda tinggi $10 \mathrm{~cm}$ dari jalur kendaraan bermotor. Untuk memberikan keamanan bagi pejalan kaki, terdapat ruang pembatas dari badan jalan yang ditanami vegetasi pengarah seperti Palem raja untuk memberikan kesan rapi dan terarah menuju landmark kampus yang berfungsi sebagai peneduh, namun juga memanfaatkan bayangan peneduh dari pohon yang berada di halaman fakultas disisi luar koridor. Ruas utara ini memiliki 2 (dua) simpangan jalan pada sisi utara yang menghubungkan ke bangunan landmark, tetapi pada persimpangannya belum ada instrumen penyeberangan bagi pejalan kaki seperti zebra cross yang menuju Widya Puraya. Atribut bagi penyandang disabilitas berupa guiding block diletakkan pada dititik-titik tertentu, sehingga belum mengakomodasi untuk jarak yang jauh. Kondisi fisik jalur pejalan kaki ruas utara memiliki lebar lebih dari 1,8 meter yang artinya memenuhi lebar minimum untuk ruang gerak pejalan kaki yang bebas hambatan. kemiringan relatif datar dengan permukaan yang menurun ke arah utara. 


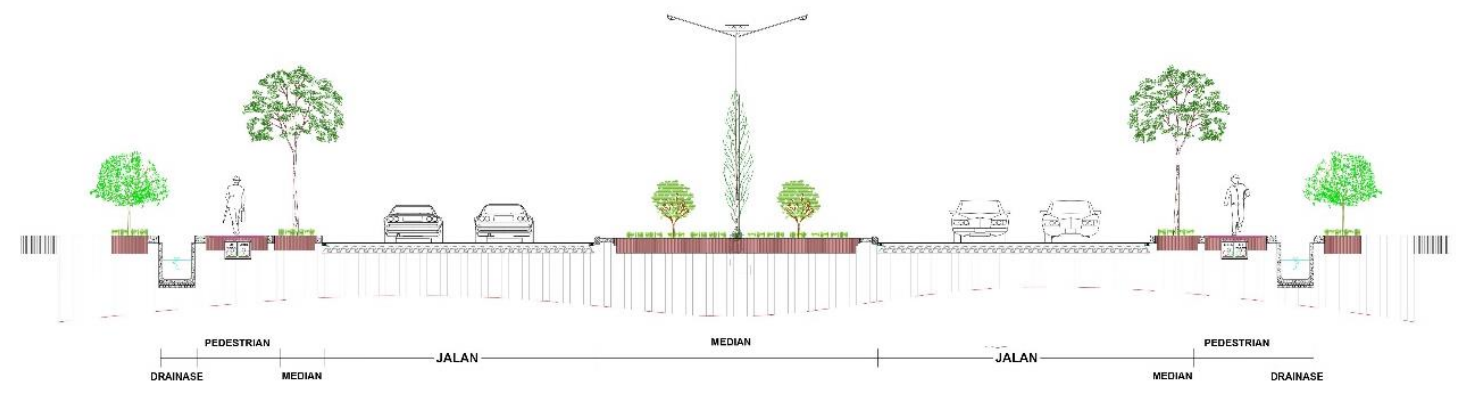

Gambar 4. Penampang koridor jalan utama ruas utara kampus

\section{Ruas Selatan}

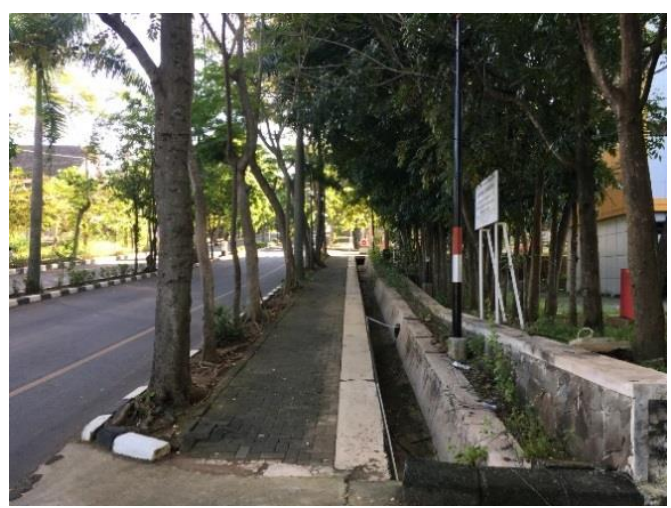

Gambar 5. Jalur pejalan kaki pada koridor jalan utama kampus ruas selatan

Letak jalur pejalan kaki terdapat pada kedua sisi jalan mulai dari gerbang masuk kampus dengan bentuk sidewalk yang menempel pada jalan utama. Fasilitas keamanan bagi pengguna jalur pejalan kaki disediakan pemisah jalur, berupa ruang vegetasi dengan beda lebih tinggi $10 \mathrm{~cm}$ yang berfungsi sebagai pagar untuk melindungi pejalan kaki dari laju kendaraan bermotor. Vegetasi yang digunakan adalah Pohon Flamboyan dengan tinggi rata-rata lebih dari 4 meter yang menciptakan bayangan peneduh dari terik matahari. Ruas selatan ini menghubungkan jalan utama dengan jalur lingkar luar Undip dan koridor penghubung antarfakultas, serta sebagai tampilan awal Kampus Tembalang. Ruas selatan belum memiliki instrumen bagi penyandang disabilitas atau bangku untuk beristirahat, melihat kondisi fisik lahan yang cenderung menanjak ke arah utara dan lebarnya tidak sampai 1,5 meter, yang artinya tidak cukup ruang bagi pejalan kaki untuk bergerak bebas dan pengguna jalur yang menyandang disabilitas harus menggunakan bantuan untuk melewati koridor awal ini.

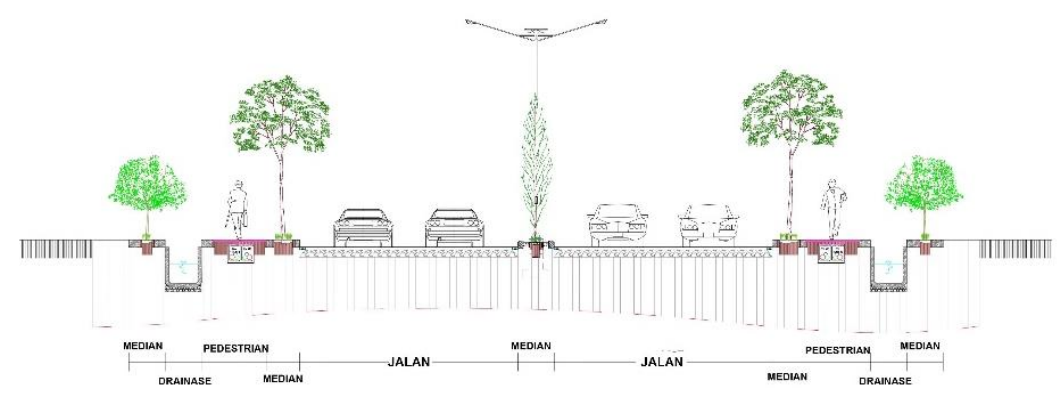

Gambar 6. Penampang koridor jalan utama ruas selatan kampus

\section{Koridor Penghubung Antarfakultas}

Koridor Penghubung Antarfakultas terbentang sepanjang 2.041,29 meter terbagi oleh koridor jalan utama menjadi sisi barat dan timur. Koridor pada ruas barat menghubungkan Sekolah Vokasi, Fakultas Ilmu Budaya, Fakultas Hukum, Fakultas Ilmu Sosial dan Ilmu Politik (FISIP), dan Fakultas Teknik. Sedangkan koridor ruas timur menghubungkan Fakultas Psikologi, Fakultas Ekonomi, Fakultas Sains dan Matematika (FSM), Fakultas Kesehatan Masyarakat (FKM), Fakultas Kedokteran, Fakultas Perikanan dan Kelautan (FPIK), Fakultas Teknik, dan Fakultas Peternakan dan Pertanian (FPP). 


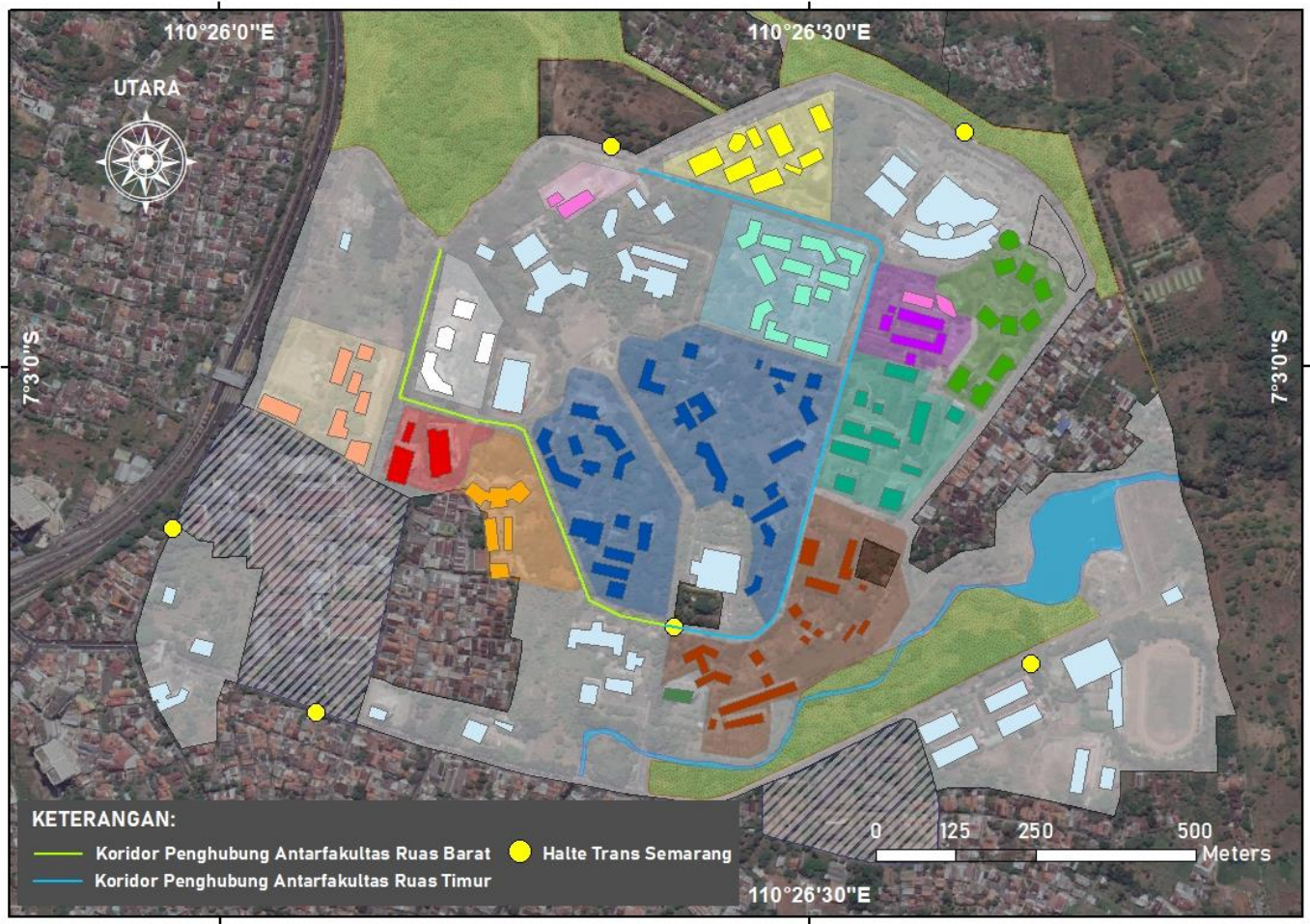

Gambar 7. Peta jalan penghubung antarfakultas kampus Undip

\section{Ruas Barat}

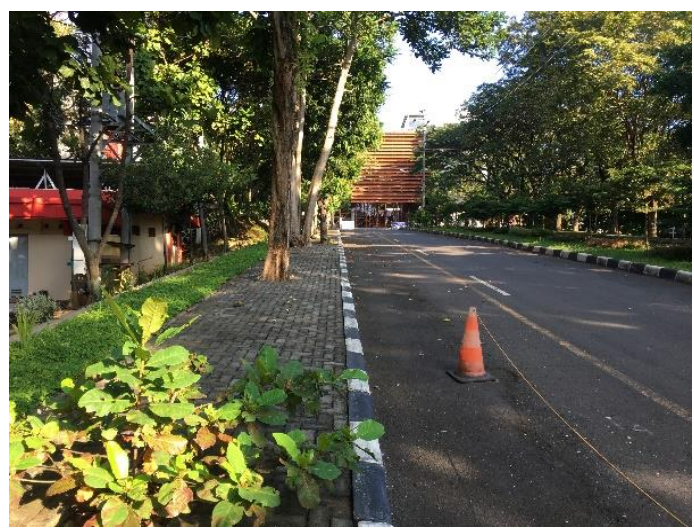

Gambar 8. Jalur pejalan kaki pada koridor antarfakultas ruas barat

Koridor penghubung antarfakultas ruas barat sepanjang 852,78 meter. Peletakan ruang pejalan kaki pada kondisi aktual di lapangan, ada pada kedua sisi jalan, tetapi jalur pejalan kaki hanya terdapat pada sisi Fakultas Hukum, FISIP, dan Fakultas Ilmu Budaya yang terhubung dengan koridor jalan utama sepanjang 328,02 meter (38,47\%) dengan bentuk sidewalk atau trotoar namun belum mencakup pada Fakultas Teknik, dan Sekolah Vokasi. Lebar jalur pejalan kaki yang ada di ruas barat adalah 2 meter yang dilengkapi vegetasi peneduh berupa Pohon Ketapang yang memiliki bentang dan daun lebar untuk menciptakan bayang peneduh dari matahari bagi pejalan kaki namun letaknya menyatu ditengah-tengah jalur, sehingga mobilitas pejalan kaki menjadi terbatas karena terhalang oleh batang pohon.

Pergantian moda transportasi umum masih perlu menyambungkan jalur pejalan kaki ke koridor lingkar luar pada sisi utara, namun belum memiliki fasilitas penyeberangan seperti zebra cross menuju jalur lingkar luar maupun bagi pejalan kaki yang ingin berpindah ke sisi jalan yang lain. Fasilitas guiding block untuk penyandang disabilitas tidak berlanjut dari koridor jalan utama untuk koridor antarfakultas ruas barat. Lampu penerangan jalan berada di tengah-tengah pulau jalan pada sepanjang koridor, tetapi bangku atau plaza/taman untuk beristirahat terletak di dalam masing-masing fakultas, sehingga perlu akses menuju ke dalam halaman fakultas. 


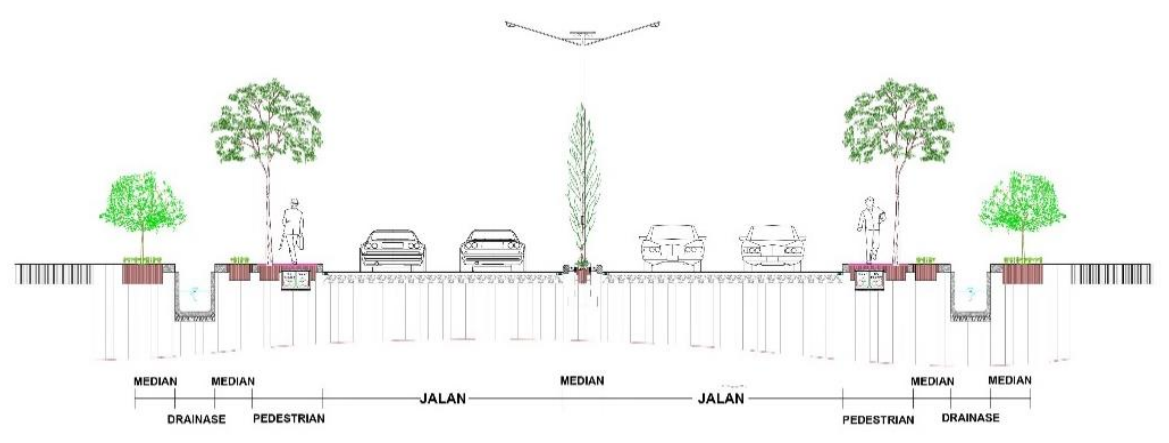

Gambar 9. Penampang koridor antarfakultas ruas barat kampus

\section{Ruas Timur}

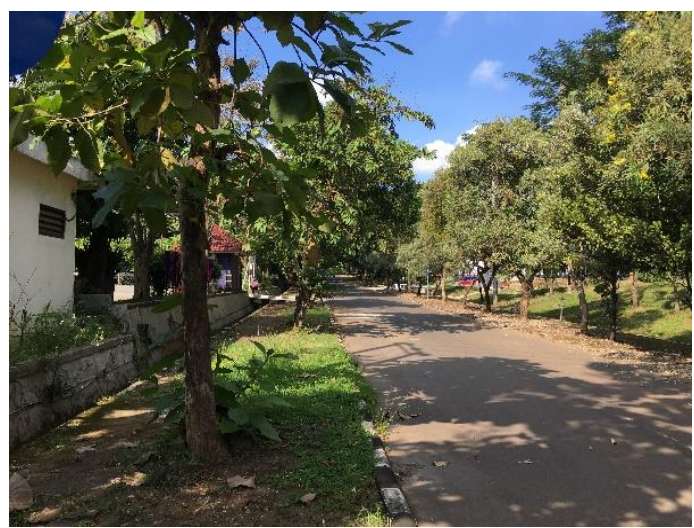

Gambar 10. Jalur pejalan kaki pada koridor antarfakultas ruas timur

Jalur pejalan kaki yang ada di ruas timur pada koridor penghubung antarfakultas terletak di kedua sisi jalan dengan panjang koridor mencapai 1.057,15 meter, 1.188,53 meter (88,95\%) sudah dilengkapi dengan jalur pejalan kaki yang berbentuk sidewalk pada sisi jalan. Ruas timur menghubungkan Fakultas Psikologi, Fakultas Ekonomika dan Bisnis (FEB), Fakultas Sains dan Matematik (FSM), Fakultas Kedokteran, Fakultas Perikanan dan Kelautan (FPIK), Fakultas Teknik dan Fakultas Peternakan dan Pertanian (FPP). Sesuai kondisi yang ada di lapangan, vegetasi pada koridor timur ini berupa Pohon Trembesi dengan bentang yang lebar mampu memberikan peneduh bagi pengguna jalur pejalan kaki serta Pohon Johar yang berfungsi untuk estetika. Sisi paling utara yang berdekatan dengan FEB digunakan pohon trembesi sebagai vegetasi peneduh, yang letaknya ditengah-tengah jalur pejalan kaki, sehingga mengurangi ruang gerak pengguna jalur. sedangkan pada sisi FSM hingga Teknik, didominasi pohon johar sebagai peneduh yang berfungsi juga sebagai pagar pelindung pejalan kaki dari laju kendaraan bermotor. Fasilitas zebra cross atau penyeberangan jalan menuju plaza pedestrian terletak dipersimpangan FPIK, Fakultas Teknik, dan FSM. Pada ruas timur ini jalur pejalan kaki belum dilengkapi dengan guiding block, bangku maupun shelter untuk beristirahat. Kontur relatif datar dengan sisi bagian selatan yang berbukit, sedikit menanjak menuju koridor jalur utama kampus.

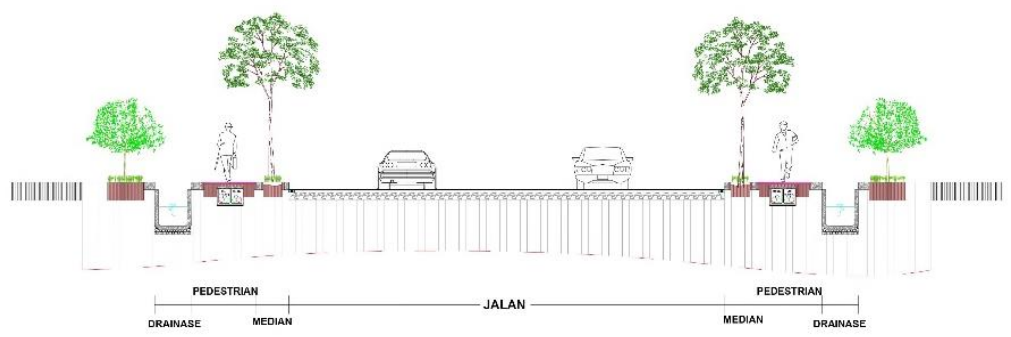

Gambar 11. Penampang koridor antarfakultas ruas timur kampus 


\section{KESIMPULAN}

Undip menempati peringkat ke-4 kampus terhijau secara nasional oleh UI Greenmetric masih perlu penataan kembali pada landsekapnya guna menunjang kenyamanan bagi sivitas akademika. Penataan jalur pejalan kaki yang ada di Kampus Undip Tembalang hampir di setiap jalur pejalan kaki di Kampus Tembalang Undip memiliki vegetasi peneduh, namun perlu penyesuaian kondisi jalur pejalan kaki tersebut agar dapat memberi ruang bagi pejalan kaki dan komunitas kampus yang nyaman serta menimbulkan kemauan untuk berjalan kaki, mengingat transportasi berkelanjutan merupakan inti dari kawasan green campus. Penambahan bangku atau shelter setiap 500 meter ruas jalan yang tujuannya untuk tempat istirahat/berteduh untuk pejalan kaki. Beberapa ruas yang belum tersambung perlu tata kembali agar konektivitasnya tidak terputus antarkoridor yang memudahkan para mahasiswa, dosen, maupun tendik bergerak pada penghubung ruang publik. Mengingat faktor kenyamanan merupakan dorongan utama bagi seseorang untuk melakukan pejalanan dengan berjalan kaki. Fasilitas jalur pejalan kaki yang bebas, tanpa hambatan ataupun risiko bahaya akan memiliki banyak manfaat yang baik secara langusng maupun tidak langsung dari bidang lingkungan, ekonomi, dan kesehatan (sustainability).

\section{DAFTAR PUSTAKA}

Cambra, P., \& Moura, F. (2020). How does walkability change relate to walking behavior change? Effects of a street improvement in pedestrian volumes and walking experience. Journal of Transport and Health, 16(November 2019), 100797. https://doi.org/10.1016/j.jth.2019.100797

Corazza, M. V., Di Mascio, P., \& Moretti, L. (2016). Managing sidewalk pavement maintenance: A case study to increase pedestrian safety. Journal of Traffic and Transportation Engineering (English Edition), 3(3), 203-214. https://doi.org/10.1016/j.jtte.2016.04.001

D'Orso, G., \& Migliore, M. (2020). A GIS-based method for evaluating the walkability of a pedestrian environment and prioritised investments. Journal of Transport Geography, 82(July 2019), 102555. https://doi.org/10.1016/j.jtrangeo.2019.102555

Göçer, Ö., Göçer, K., Özcan, B., Bakovic, M., \& Kıraç, M. F. (2019). Pedestrian tracking in outdoor spaces of a suburban university campus for the investigation of occupancy patterns. Sustainable Cities and Society, 45(November 2018), 131-142. https://doi.org/10.1016/j.scs.2018.11.006

Pedoman Perencanaan, Penyediaan, dan Pemanfaatan Prasarana dan Sarana Jaringan Pejalan Kaki di Kawasan Perkotaan, 2013 Menteri Pekerjaan Umum Republik Indonesia 8 (2014). http://pugpupr.pu.go.id/_uploads/Produk_Pengaturan/Permen PUPR No 03-2014.pdf

Leal Filho, W., Shiel, C., do Paço, A., \& Brandli, L. (2015). Putting sustainable development in practice: Campus greening as a tool for institutional sustainability efforts. In Sustainability in Higher Education. Elsevier Ltd. https://doi.org/10.1016/B978-0-08-100367-1.00001-9

Marrone, P., Orsini, F., Asdrubali, F., \& Guattari, C. (2018). Environmental performance of universities: Proposal for implementing campus urban morphology as an evaluation parameter in Green Metric. Sustainable Cities and Society, 42(July), 226-239. https://doi.org/10.1016/j.scs.2018.07.012

Murwadi, H., \& Dewancker, B. (2017). Study of quassessment model for campus pedestrian ways, case study: Sidewalk of the University of Lampung. Sustainability (Switzerland), 9(12), 1-16. https://doi.org/10.3390/su9122285

Rafiemanzelat, R., Emadi, M. I., \& Kamali, A. J. (2017). City sustainability: the influence of walkability on built environments. Transportation Research Procedia, 24, 97-104. https://doi.org/10.1016/j.trpro.2017.05.074

Ridhosari, B., \& Rahman, A. (2020). Carbon footprint assessment at Universitas Pertamina from the scope of electricity, transportation, and waste generation: Toward a green campus and promotion of environmental sustainability. Journal of Cleaner Production, 246, 119172. https://doi.org/10.1016/j.jclepro.2019.119172

Setyowati, E., Harani, A. R., \& Falah, Y. N. (2013). The Application of Pedestrian Ways Design Concepts as an Implementation of Sustainable Urban Open Spaces. Procedia - Social and Behavioral Sciences, 85, 345-355. https://doi.org/10.1016/j.sbspro.2013.08.364 
Shamsuddin, S., Hassan, N. R. A., \& Bilyamin, S. F. I. (2012). Walkable Environment in Increasing the Liveability of a City. Procedia - Social and Behavioral Sciences, 50(July), 167-178. https://doi.org/10.1016/j.sbspro.2012.08.025

Soni, N., \& Soni, N. (2016). Benefits of pedestrianization and warrants to pedestrianize an area. Land Use Policy, 57(5), 139-150. https://doi.org/10.1016/j.landusepol.2016.05.009

Wimala, M., Akmalah, E., Irawati, I., \& Sururi, M. R. (2016). Overcoming the Obstacles to Green Campus Implementation in Indonesia. June.

Yilmaz, H., Yilmaz, S., Yavaş, M., Mutlu, E., \& Koç, A. (2016). Climate-sensitive Pavement Modelling for Pedestrian Ways. Procedia Engineering, 169, 408-415. https://doi.org/10.1016/j.proeng.2016.10.050 